\title{
The Perceived Value of College Physics Textbooks: \\ Students and Instructors May Not See Eye to Eye
}

\author{
Noah Podolefsky and Noah Finkelstein \\ University of Colorado
}

(C) 2006, Podolefsky \& Finkelstein. All rights reserved. Do not quote without permission of the authors.

To Appear in The Physics Teacher (likely September 2006)

\begin{abstract}
This paper describes a study of student textbook use in four introductory college physics courses. Students were surveyed to find out how much they read their physics textbook, when they read, what effect (if any) this had on their performance, and if different instructors/textbooks made a difference. Survey results indicate that while over $97 \%$ of our students buy the required textbook, less than $41 \%$ regularly read, $60 \%$ read after lecture rather than before, and there is little (or no) correlation between reading habits and course grade. Further analysis of how and why students read indicates little or no variation in the perceived value of the textbook for course components tightly coupled to grades. We found that these results were strikingly similar across conceptual-, algebra-, and calculus-based courses with different instructors and textbooks.
\end{abstract}




\section{Introduction}

Physics instructors generally tell their students to read the textbook assignments before coming to lecture (e.g. this is often stated on course syllabi). While the textbook is a part of nearly every physics course, it is not clear how students use it. Only a small number of previous studies have asked how students actually use their textbooks. One such study measured the amount students read a particular introductory physics textbook at two institutions. This study showed that at one institution less than $40 \%$ of students in introductory physics regularly read the textbook assignments, but that at an institution where students were required to submit reading exercises, 55\% of students regularly read the textbook. ${ }^{1}$ However, this study did not explore the effects of reading, or whether different courses or different textbooks affected student reading habits. Another study, in chemistry, reported a significant correlation between time spent reading and course grade for general chemistry students; lower performing students actually read more. This study, however, also reported that for organic chemistry students, there was no correlation between time spent reading and course grade ${ }^{2}$.

These results led us to ask how much students read at our own university, and what effect (if any) this had on their performance. Continuing where previous studies left off, we asked when students read, how and why they use the textbook, and if different instructors/textbooks made a difference. We found that while over $97 \%$ of our students buy the required textbook, less than $41 \%$ regularly read, $60 \%$ read after lecture rather than before, and there is little (or no) correlation between reading habits and course grade. Whether they read regularly or not, most students agreed that the textbook was 
useful for doing homework and studying for exams. However, only regular readers used the textbook to understand lecture, or read word-for-word. The rest used the textbook mainly as a reference. We found that these results were strikingly similar across conceptual-, algebra-, and calculus-based courses with different instructors and textbooks.

\section{Asking the Students}

To find out how and when students read, we developed a short survey, which contains 14 multiple choice and free-response questions. The questions address how, when, and why students use the textbook. Administered on-line, students generally take less than 5 minutes to complete the survey. The survey was administered mid-way through the semester.

Here, we present detailed responses to the following two questions. How often do students read the textbook assignments - often (more than $80 \%$ ), sometimes (20-80\%), or rarely (less than 20\%)? When do students read - before lecture, equally before and after, or after lecture? We also summarize responses to questions of how (e.g. reading wordfor-word) and why (e.g. for understanding lecture) students read the textbook. (The complete survey and additional detailed results can be found at http://per.colorado.edu/textbooks/) 


\section{The Courses}

We surveyed students in four introductory college physics courses: 2 calculus-based, 1 algebra-based, and 1 conceptual-based. Table 1 lists information for the courses. Numbers in parentheses indicate the numbers of students responding on the survey. The grade distributions for students taking the survey had a high correlation $(r>0.9)$ with the grade distribution for each whole class, assuring a representative crosssection of each course. One of the calculus-based courses ran in the fall of 2004. The other three courses ran in the spring of 2005.

These courses represent the canonical ones, the traditionally taught introductory physics sequences taught in many physics departments. Each course was the second semester of a two-semester sequence. The calculus- and algebra-based courses all had large enrollments, while the conceptually-based course had a smaller enrollment. The lectures all made extensive use of peer-instruction ${ }^{3}$ and personal electronic response systems (PERS $\left.{ }^{4}\right)$. Otherwise, lectures were the traditional style, with instructor lecturing from the front of the room with chalk, overheads, and the occasional demonstration. The calculus- and algebra-based courses included weekly recitations, and students completed back-of-the-book style homework problems with an electronic system (CAPA). Hour exams, given several times throughout each semester, were also in the traditional style, including a span of problems from the back-of-the-chapter style quantitative problems to problems focusing on conceptual analysis. The courses all used standard textbooks appropriate for each level. While students were told to read in all four courses (e.g. on course syllabi), a direct stimulus 
to promote reading (i.e. reading quizzes) was given only in the conceptually-based course.

\section{What Students Said}

The responses to how often students read are shown in Figure 1a. The vertical axis shows the fraction of students in each course that reported reading often, sometimes, or rarely. The colored bars correspond to each course. The average fractions across all courses are shown below the x-axis. In general, the differences between the four courses were not statistically significant. Any course category of response that was different from the others $(\mathrm{p}<0.05)$ is indicated with an “*”. On average, 37\% of students responded that they read often, $38 \%$ sometimes, and $25 \%$ rarely.

Data on when students read are shown in Figure 1b. The vertical axis shows the fraction of students in each course that reported reading before, equally before and after, or after lecture. Again, the colored bars correspond to each course, and statistically significant differences are indicated with an “*”. On average, $18 \%$ of students responded that they read before, $21 \%$ equally before and after, and $61 \%$ after. There is a distinct bias in the results for the conceptually-based course. About twice as many students read before than after lecture, and we suspect that this is due to it being the only course in which reading quizzes were given in lecture. The other three courses make extensive use of PERS, but do not have quizzes specifically on the reading materials. 
From the survey responses, it is possible to ask how many students read often and before lecture. We found that across all courses, less than $13 \%$ of students fell into the often/before category. In other words, only a small fraction of students follow the advice given to them on the course syllabi.

Given the small fraction of students regularly reading the textbook, we might consider how reading correlates with course grade. Figure 2 shows the average grades (fraction of total possible points) for students in each course, depending on whether they read often, sometimes, or rarely. The overall average grades in both calculus-based courses are very similar, while grades in the algebra- and conceptually-based courses were slightly higher. However, for algebra- and calculus-based courses, we found no significant correlation between course grade and how much students read (average correlation coefficient $\mathrm{r}=$ 0.07). For the conceptual-based course, there is a moderate correlation $(r=0.47)$ between course grade and how often students read the textbook.

Three key points stand out in our results. 1) Only 37\% or students regularly read the textbook, and less than $13 \%$ read often and before lecture. 2) There is no correlation between reading habits and course grade in the algebra- and calculus-based courses. 3) These results are repeatable across four physics courses at different levels, with different instructors and textbooks.

Examining these results, we turn to the data on how and why students read. These results are summarized in Table 2. Table 2 shows the fraction of students who agreed that they 
used the textbook in various ways, depending on whether they read often or rarely (e.g. $60 \%$ of students who read often agreed that the textbook was useful for studying for exams). When asked if they found the textbook useful for studying for exams and solving homework problems, students who read often and rarely agreed equally (at the $\mathrm{p}=0.05$ significance level). However, when asked if the textbook was useful for understanding lecture, students who read often agreed significantly more than students who read rarely. Students who read often were also more likely to read word-for-word and out of personal interest. Thus, it appears that all students used the textbook for elements of the course that were tightly coupled to course grade. However, only select students (who read often) took the time to read the textbook for other reasons. Surprisingly, we found that these select students did not receive significantly higher average course grades compared to their non-reading peers.

\section{Discussion}

We turn to a more qualitative analysis to begin to explore why so many students do not read, and why we find no correlation between reading habits and course grade. Interviews and analysis of student written responses are suggestive of at least two plausible explanations: 1) Students optimize their time by drawing on resources that they find most productive for success in a course, the textbook being only one of many possible resources; and 2) The textbook is not tightly coupled to elements of the courses that directly affect students’ grades. In this case, in terms of performance, it may not matter how or how much students read. 
The first explanation emphasizes characteristic differences among students. Some students with similar grades told us they used the textbook in very different ways. While some "A" students read "word-for-word with understanding" and "pause after a concept and then think about it," other "A" students "think that the majority of the material can be learned from attending class, actively participating, going to recitation and asking questions, and doing the [homework].” They “don’t ever read the text” except for "looking up constants." On the other hand, some " $\mathrm{D}$ ” students tell us they "read all the material in the book, so I guess I did it about right.” It would seem there are many ways that students use their textbooks, and perhaps there is no single right way to read.. Clearly, some students do self-select different ways of using the textbook, sometimes productively and sometimes not.

The second explanation of textbook use centers around course structure. These courses (and others) may not emphasize the use of the textbook. More precisely, different course components may vary in the degree to which they draw from the textbook. One student told us in an interview that the textbook was "really useful for [homework]" but that "the material on the exams is similar to the format of the lecture but not so much similar to the book.” In the algebra- and calculus-based courses we surveyed, there was generally a much broader spread in exam grades than homework grades. In light of this, a possible explanation is that the elements of the course where the textbook might play a major role (e.g. homework) do not contribute to grade differences as much as other elements (e.g. exams). 
These two perspectives, students optimizing approach and the structural organization of the course and resources, are no doubt tightly coupled. To be sure, we do not believe that either explanation is sufficient by itself. These results of students' use of textbooks likely stem from the complex interaction between diverse groups of students and courses with certain built in structures. Understanding the textbook's role in this interaction, and how to more (or less) tightly couple textbook use with our course goals is rich area for further study.

\section{Conclusion}

In this paper, we have addressed questions of if, when, how, and why students read their physics textbook. We have not addressed the question of whether students should read, allowing readers to draw their own conclusions on this point. What we can say is that while physics instructors perceive a high value in textbooks, students may not. Physics instructors tend to advise their students to read the textbook and read before coming to class. The conventional wisdom is that students who follow this advice will perform better overall in the course. We have found that most students do not follow this advice, and that these students are not necessarily hurt (performance-wise) compared to students who do read as they are instructed. We are not yet sure why this is, and we can only speculate. One student told us, "For the most part, I am either working [at a job] or in class from 8a-6p every day.” Thus, reading may simply be a matter of time optimization. On the other hand, it is illuminating that some students associate the lecture with exams, and the textbook with homework. No doubt, the relationship between textbooks and student learning is complex and deserves further attention. Based on the observation that 
less than $40 \%$ of students read, other researchers have suggested that "students have not figured out for themselves that reading is a potentially useful intellectual endeavor.” ${ }^{1}$ Perhaps the fact that students can get A's despite not reading sends a different message. At any rate, our findings should prompt educators to examine just what role textbooks play in their courses, particularly from the point of view of the students.

\section{Acknowledgements}

We gratefully acknowledge support from the NSF, CCLI, \#DUE 0410744 and Colorado PhysTEC, Physics Teacher Education Coalition, sponsored by the APS, AIP, and AAPT. We also thank Professors Steven Pollock, Michael Dubson, and Paul Beale, and all the members of the Physics Education Research Group at Colorado for their assistance and valuable discussions. 
Table 1. Course information

\begin{tabular}{|l|l|l|}
\hline Course & Textbook & Enrollment \\
\hline Calculus-based (Fall 04) & $\begin{array}{l}\text { Fundamentals of Physics, Halliday, } \\
\text { Resnick, and Walker }\end{array}$ & $479(402)$ \\
\hline Calculus-based (Spring 05) & Physics, Knight & \\
\hline Algebra-based (Spring 05) & Physics, Giancolli & $334(215)$ \\
\hline Conceptual-based (Spring 05) & $\begin{array}{l}\text { How Things Work; The Physics of } \\
\text { Everyday Life, Bloomfield }\end{array}$ & $423(183)$ \\
\hline
\end{tabular}

Table 2. How students use their textbooks

\begin{tabular}{|ll|c|c|c|c|}
\cline { 3 - 6 } \multicolumn{1}{l|}{} & & Calc Fa 04 & Calc Sp 05 & Algebra & Conceptual \\
\hline \multirow{2}{*}{ Studying for Exams } & Often & $60 \%$ & 58 & 70 & 8 \\
\cline { 3 - 6 } & Rarely & 52 & 52 & 61 & 43 \\
\hline \multirow{2}{*}{ Solving Homework Problems } & Often & 64 & 62 & 74 & 33 \\
\cline { 3 - 6 } & Rarely & 63 & 64 & 68 & 43 \\
\hline \multirow{2}{*}{ Understanding Lecture } & Often & 56 & 69 & 76 & 17 \\
\cline { 3 - 6 } & Rarely & 25 & 30 & 26 & 14 \\
\hline \multirow{2}{*}{ Read out of Personal Interest } & Often & 47 & 52 & 45 & 25 \\
\cline { 3 - 6 } & Rarely & 37 & 30 & 30 & 29 \\
\hline \multirow{2}{*}{ Read Word-for-word } & Often & 73 & 74 & 55 & 58 \\
\cline { 3 - 6 } & Rarely & 13 & 13 & 10 & 43 \\
\hline
\end{tabular}




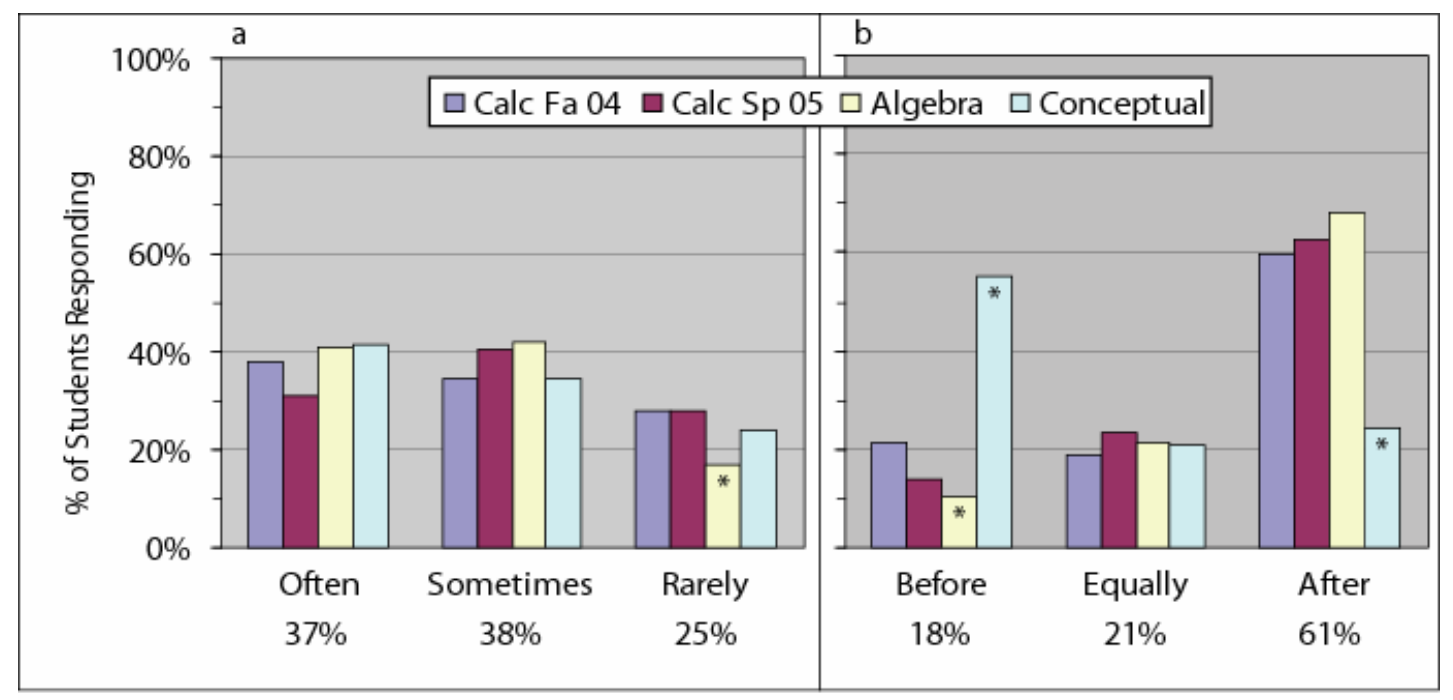

Figure 1

Figure 1. a. How often students read. b. When students read. Numbers below the $\mathrm{x}$-axis are the average for each category (e.g. $37 \%$ of all students responded “often”). “*” indicates a statistically significant $(p<0.05)$ difference from the average in each category.

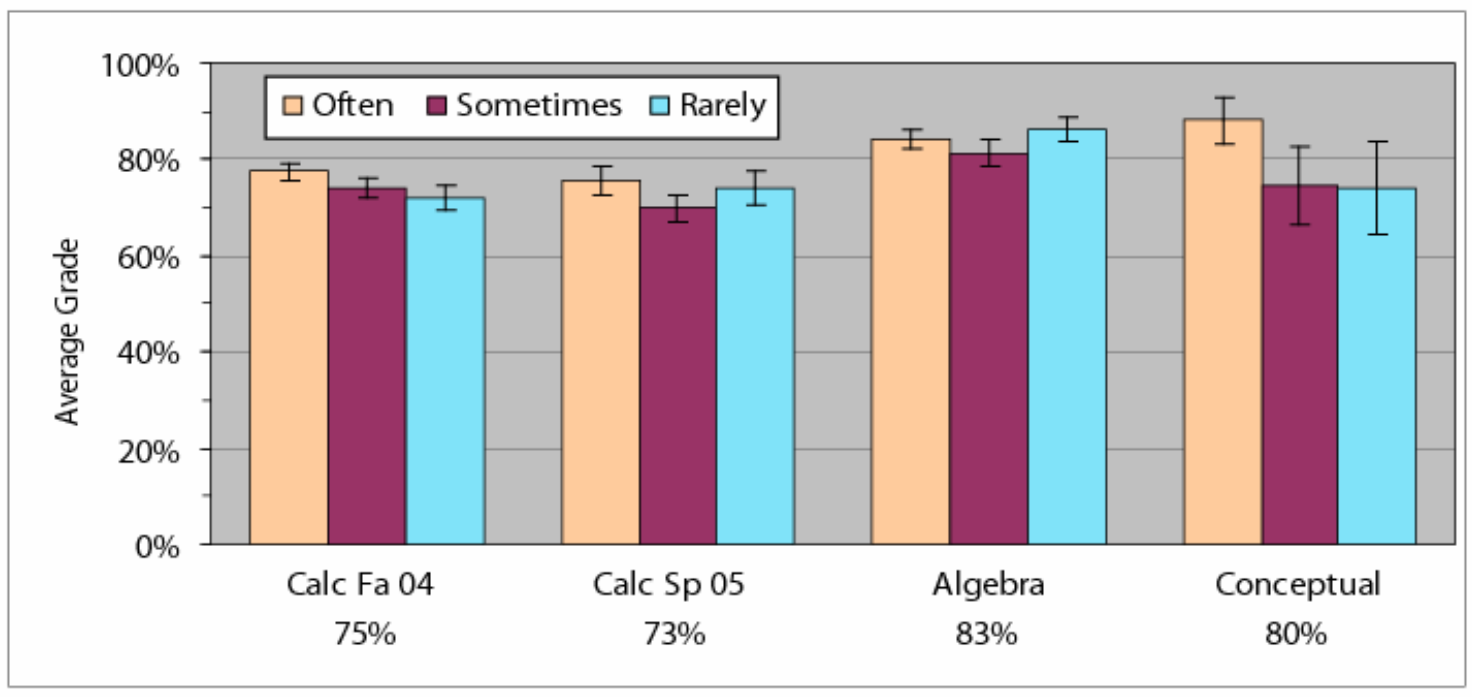

Figure 2

Figure 2. Average grade vs. reading habits for each course. Error bars represent $95 \%$ confidence intervals. Numbers below the $\mathrm{x}$-axis are the average grade in each course. 
References

${ }^{1}$ K. Cummings, T. French, P.J. Cooney, “Student Textbook Use in Introductory Physics,” PERC Proceedings (2002).

${ }^{2}$ B.D Smith, D.C. Jacobs, “TextRev: A Window into How General and Organic Chemistry Students Use Textbook Resources,” J. Chem. Educ. Research 80, 99 (Jan. 2003).

${ }^{3}$ E. Mazur, Peer Instruction: A User’s Manual (Prentice Hall, New Jersey, 1997).

${ }^{4}$ H-ITT; see http://www.h-itt.com/.

${ }^{5}$ D. Halliday, R. Resnick, J. Walker, Fundamentals of Physics, $7^{\text {th }}$ ed. (John Wiley \& Sons, 2004)

${ }^{6}$ R.D Knight, Physics for Scientists and Engineers. (Addison Wesley, 2003)

${ }^{7}$ D.G. Giancoli, Physics, $6^{\text {th }}$ ed. (Prentice Hall, 2004)

${ }^{8}$ L.A. Bloomfield, How Things Work: The Physics of Everyday Life, $2^{\text {nd }}$ ed. (John Wiley \& Sons, 2000) 

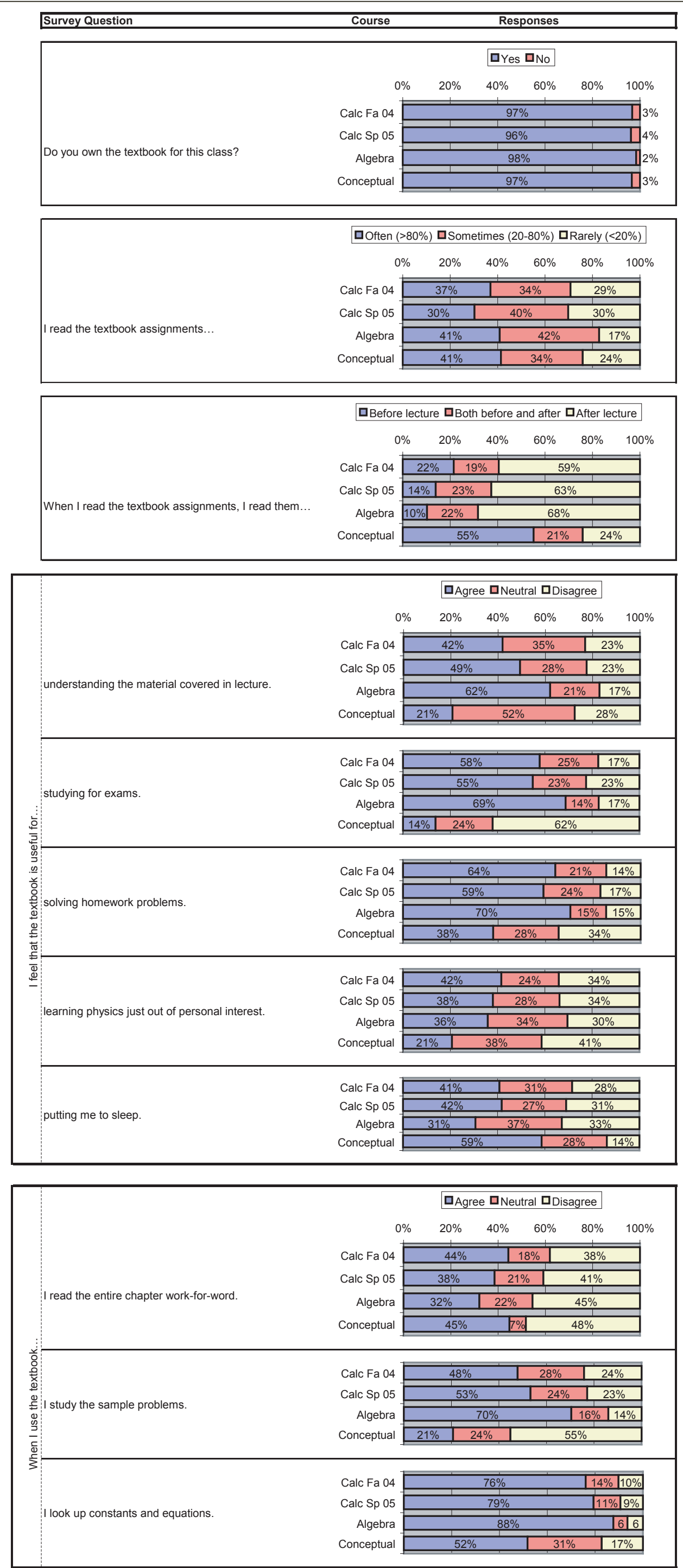

प Agree QNeutral QDisagree

\begin{tabular}{|c|c|c|c|c|c|c|}
\hline & & & Q Agree $\mathrm{QNe}$ & utral $\mathrm{QDis}$ & & \\
\hline & & $\%$ & $40 \%$ & $60 \%$ & $80 \%$ & $100 \%$ \\
\hline & Calc Fa 04 & 32 & $\%$ & $43 \%$ & $25 \%$ & \\
\hline & Calc Sp 05 & $21 \%$ & $31 \%$ & D. & $49 \%$ & \\
\hline The cost of the textbook was reasonable. & Algebra & \begin{tabular}{|l|l|l|l|l|l|l|}
10 & \\
\end{tabular} & $32 \%$ & & $9 \%$ & \\
\hline & Conceptual & \begin{tabular}{|l|l|}
$14 \%$ \\
\end{tabular} & $29 \%$ & & $57 \%$ & \\
\hline
\end{tabular}

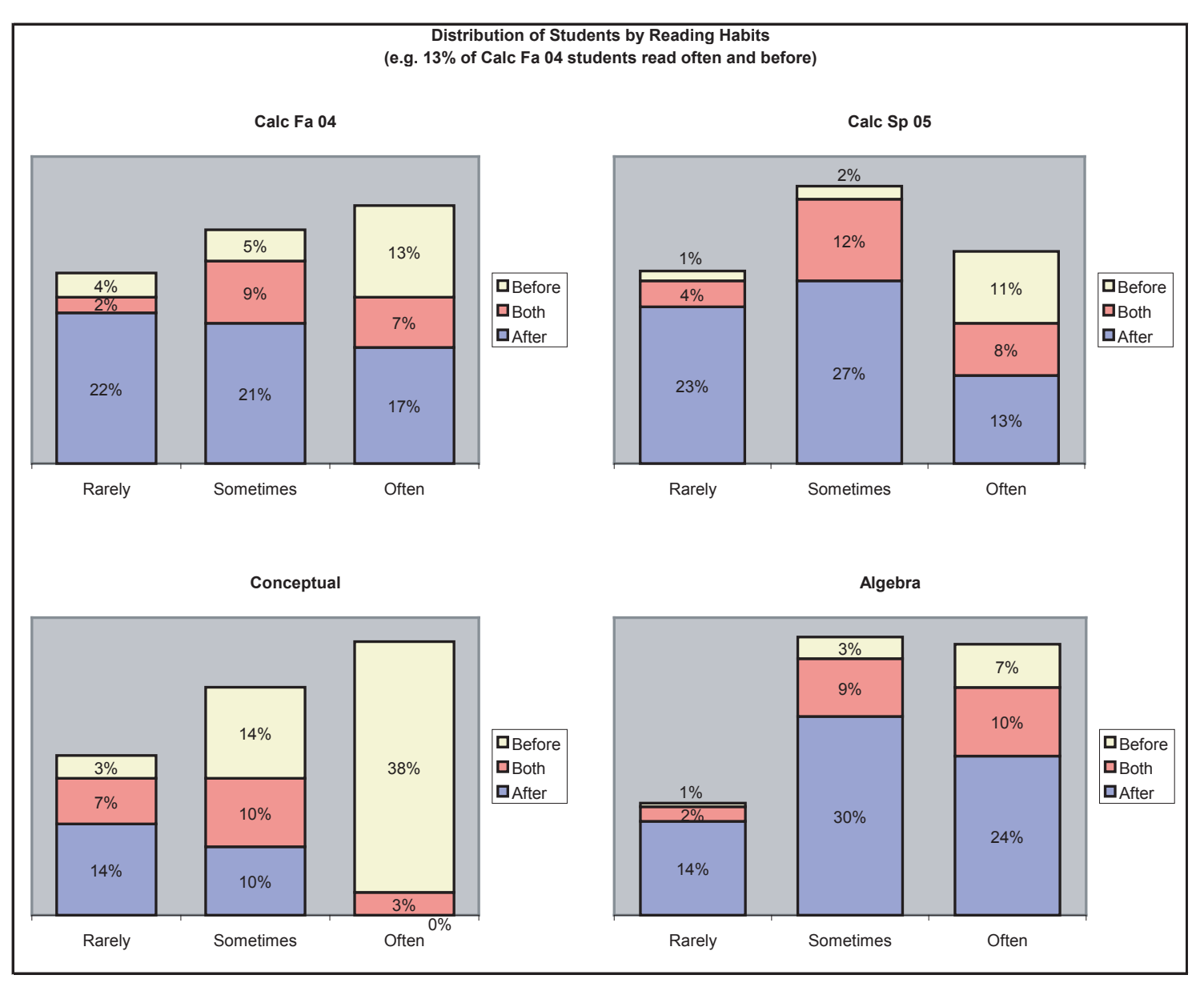

